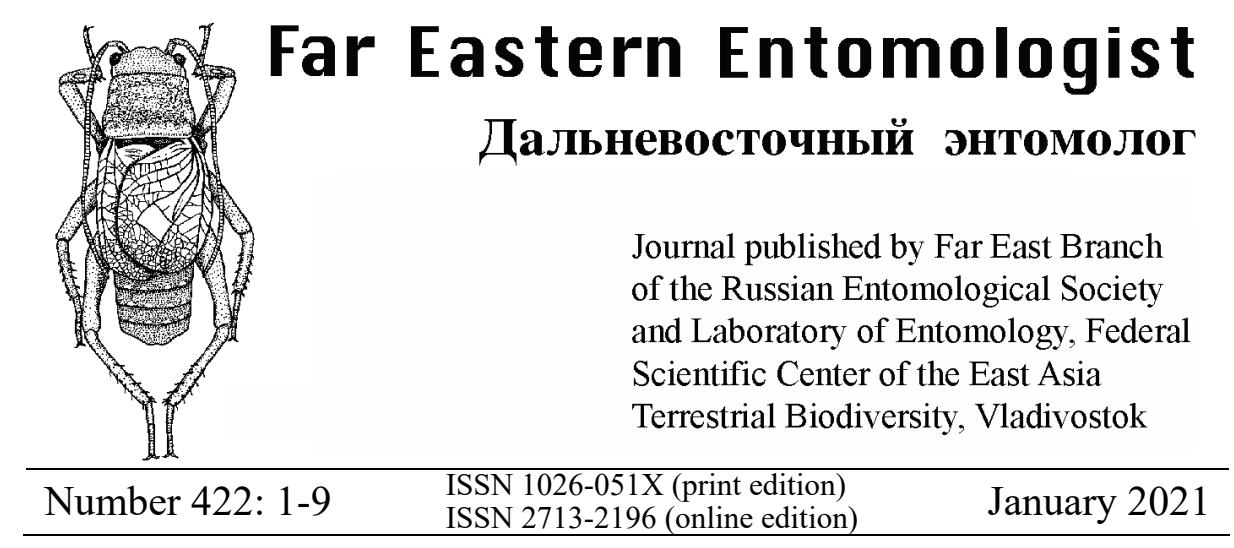

https://doi.org/10.25221/fee.422.1

http://zoobank.org/References/55c6a401-823f-498c-b2f6-2ff45bf6c247

\title{
A NEW SPECIES OF THE RHAGOVELIA SARAWAKENSIS SPECIES GROUP (HEMIPTERA: VELIIDAE) FROM CAMBODIA
}

\section{H. Zettel ${ }^{1)}$, A. Laciny ${ }^{1)}$, C. V. Pangantihon ${ }^{2)}$}

1) Entomological Department, Natural History Museum Vienna, Burgring 7, 1010 Vienna, Austria.E-mail: herbert.zettel@nhm-wien.ac.at;_alice.laciny@nhmwien.ac.at

2) Biology Department, School of Science \& Engineering, Ateneo de Manila University, Loyola Heights, Quezon City, 1101 Philippines. E-mail: aquatic. pangantihon@gmail.com

Summary. Rhagovelia freitagi Zettel, Laciny et Pangantihon, sp. n. is described and illustrated from Cambodia. The new species belongs to the Rhagovelia sarawakensis species group. A key to the species of this group that are presently known from Cambodia, Laos and Vietnam is also given.

Key words: bugs, Gerromorpha, Rhagoveliinae, Rhagovelia, taxonomy, new species, key, Indochina.

Г. Зеттел, А. Лацини, К. В. Пангантихон. Новый вид группы Rhagovelia sarawakensis (Hemiptera: Veliidae) из Камбоджи // Дальневосточный энтомолог. 2021. N 422. C. 1-9.

Резюме. Из Камбоджи описан новый вид Rhagovelia freitagi Zettel, Laciny et Pangantihon, sp. n. Этот вид относится к группе видов Rhagovelia sarawakensis. Также приведена определительная таблица видов этой группы, известных из Камбоджи, Лаоса и Вьетнама. 


\section{INTRODUCTION}

This taxonomic study was initiated by a faunistic survey of the water bug fauna (Hemiptera) of Cambodia. Until a few years ago, the Cambodian fauna of Nepomorpha and Gerromorpha was almost unstudied. However, recently two faunistic papers appeared (Zettel et al., 2017; Polhemus, 2017), containing checklists and descriptions of new species. It is planned that the survey of the country's aquatic fauna will be continued, and new material is already available for study.

In the checklist by Polhemus (2017), Rhagovelia tebakang Polhemus et Polhemus, 1988 was reported from Cambodia. This was astonishing, because this species was described from a few specimens collected from a small area on Borneo (Sarawak; Polhemus \& Polhemus, 1988) and otherwise not recorded since, neither from other parts of Borneo nor from the well studied Malay Peninsula. Most Rhagovelia species have very poor dispersal abilities and therefore small distribution areas. The Rhagovelia fauna of Borneo is almost entirely endemic. Rhagovelia sondaica Polhemus et Polhemus, 1988, the only species that was previously reported from both Borneo and the Asian mainland - specifically from the Malay Peninsula - is a common and frequently collected species and also occurs on Sumatra Island. A disjunctive distribution area - as proposed by Polhemus (2017) for $R$. tebakang - has never been reported from any Rhagovelia species.

The taxonomy of the Rhagovelia sarawakensis group (sensu lato, following Polhemus, 1990; Nguyen \& Tran, 2016) is admittedly very challenging. Presently, twenty species are described from an area spanning from Sri Lanka to South Japan and the Greater Sunda Islands. In contrast to some other species groups, whose members have advanced secondary sexual characters which are very useful for species discrimination, most species of the $R$. sarawakensis group are rather uniform and have similar male genitalia and weakly modified female terminalia. A close examination of Cambodian specimens of "Rhagovelia cf. tebakang" revealed differences from the original description of $R$. tebakang, and consequently requires the taxonomic description of the material as a new species.

\section{MATERIAL AND METHODS}

The specimens were originally collected in ethanol, but part of the series was drymounted. Insects were examined with a Leica Wild M10 binocular microscope (max. $128 \times$ magnification); studies of male genitalia were conducted with an OLYMPUS BX40 compound microscope (max. 400× magnification). Drawings were made with the help of a camera lucida fixed to these microscopes. Stacked digital images were taken with a Leica DFC490 camera attached to a Leica Z16 APO zoom macroscope, using Leica Application Suite V3. Images were stacked with ZereneStacker 64-bit, and processed with Adobe Photoshop 7.0.

Measurements are given in millimetres and refer to the maximum length or width of the respective structure, if not stated otherwise. Metafemur width does not include spines. 


\section{TAXONOMY}

\section{Family Veliidae}

\section{Genus Rhagovelia Mayr, 1865}

\section{Rhagovelia freitagi Zettel, Laciny et Pangantihon, sp. n.}

http://zoobank.org/NomenclaturalActs/4bf0685c-498d-48a0-b93b-077e935dc7d4

Figs $1-8$

TYPE MATERIAL. Holotype - apterous male labelled "Cambodia: Mondulkiri Prov. Saen Monourom City, Dakdam vill., Dakdam wf., N 12²4.65' E107 $18.6^{\prime}$, 811 m, 22.XI. leg. Pangantihon P591 (MO-3)" (Natural History Museum Vienna). Paratypes: 2 apterous males, 5 apterous females collected with the holotype; 2 apterous males, 2 apterous females labelled "Cambodia: Mondulkiri Prov. Saen Monourom City, W Kroeng Saen Monourom, N 12²6.58' E10709.58', 612 m, 22.XI. leg. Pangantihon P592 (MO-4)" (Natural History Museum Vienna; Cambodian Entomology Initiatives at the Royal University of Phnom Penh; private collection of first author).

DIAGNOSIS. A species of the Rhagovelia sarawakensis group that is characterized by small size, short pronotum (apterous morph), moderately incrassate metafemur, unmodified sternites of the male, and horizontal tergite 8 of the female. Habitus slender (Figs 1, 2), size small (apterous male: 2.7-2.9 mm; apterous female: 2.8-3.1 mm). Long setae sparse. Trunk black, except pronotum anteriorly with orange mark. Coxae, trochanters, and bases of pro- and metafemora yellow (mesocoxa brownish infuscated in some specimens). Jugum moderately broad and declivitous. Black spinulae present on proepisternum, meso- and metacoxa, lacking on procoxa. - Male: mesofemur without stout spines at base of flexor side. Hind leg (Fig. 3): trochanter with a spiny tooth; femur with basal and distal row of teeth consisting of 8-10 and 8-11 teeth, respectively; tibia with strong dentition on flexor side, its teeth about as long as smaller teeth of distal row on femur. Proctiger slender (Fig. 4). Paramere (Fig. 5) with slender distal part; ventral outline beset with very long setae; apex narrowly rounded. - Female: Hindleg (Fig. 6): femur with basal and distal row of teeth consisting of 2-5 and 7-9 teeth, respectively; tibia with a few small denticles. Abdomen (Figs 7, 8) almost without modifications; connexival margins of segments 2-4 slightly thickened; tergites 6 and 7 usually with a group of few moderately long setae at middle of hind margins; tergite 8 somewhat shiny; connexival corner only slightly acute, with some long, black setae.

DESCRIPTION. APTEROUS MALE. Measurements of holotype: Body length 2.94; maximum body width (at metapleura) 1.03 . Head length 0.34 , width 0.72 ; minimum eye distance 0.15 . Pronotum length 0.20 , width 0.84 . Mesonotum length 0.59 . Lengths of antennomeres, I 0.71, II 0.35, III 0.47, IV 0.46. Lengths of leg segments: 
profemur 0.75 , protibia 0.84 , protarsus $0.02+0.03+0.18$, mesofemur 1.38 , mesotibia 1.06 , mesotarsus $0.07+0.47+0.59$, metafemur 1.16 , metatibia 1.03 , metatarsus $0.01+0.02+0.33$. Metafemur width 0.26.

Measurements of paratypes $(n=3)$. Body length 2.72-2.75; maximum body width (at metapleura) $0.95-1.02$. Head width $0.69-0.72$. Pronotum length $0.20-0.22$, width 0.81. Mesonotum length 0.56-0.58. Metafemur width 0.24-0.26.
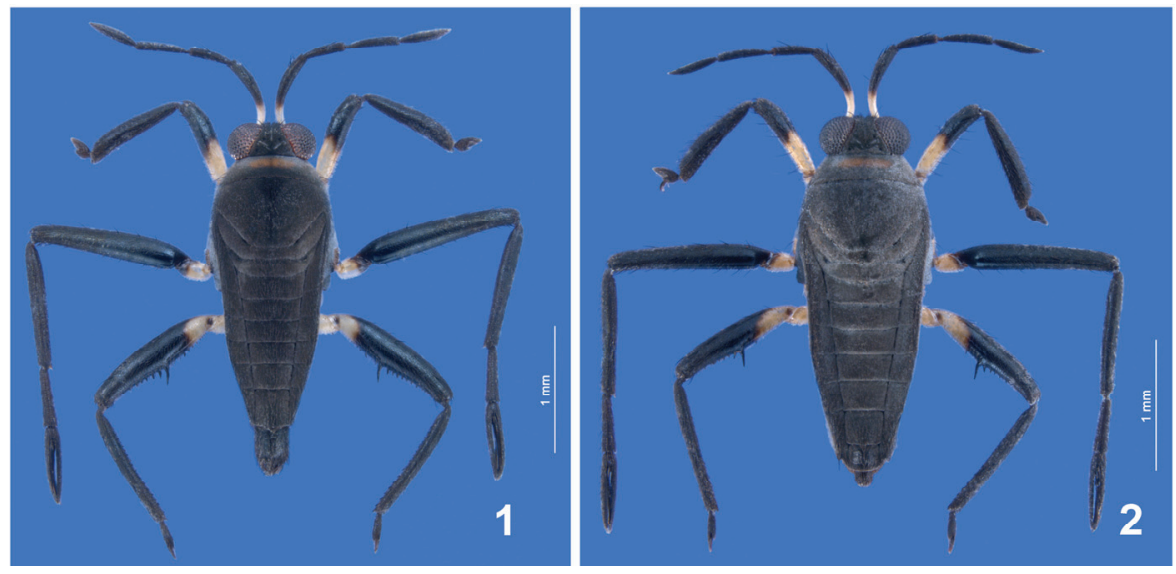

Figs 1, 2. Rhagovelia freitagi sp. n. 1 - habitus of male (paratype); 2 - the same, female (paratype) (C A. Laciny).

Colour (Fig. 1). Black. Pronotum anteromedially with transverse orange mark. Juga and base of rostrum brown. Basal third to half of antennomere 1, all coxae and trochanters, basal half of profemur and basal fifth of metafemur pale yellow.

Pilosity. Head, sides of pronotum, and dorsoposterior margin of segment 8 with few long black setae. Antennomeres 1 and 2, and femora with the usual pattern of long black setae. Hind margins of tergites and laterotergites with transverse rows of moderately long subdecumbent gray setae. Short pilosity gray, dense and appressed.

Structures. Body slender, abdomen almost evenly converging towards apex. Head broader than anterior margin of pronotum. Juga smooth and shiny, without spinulae, flat, about twice as long as broad, inclined towards antennal tubercles. Pronotum very short, along midline about 0.6 times as long as head (holotype). Mesonotum along midline 2.6-2.9 times as long as pronotum. Proepisterna bearing numerous small black spinulae.

Profemur on extensor side with hardly recognizable concavity, flexor side basally with black spinulae. Meso- and metacoxa dorsolaterally each with a group of small black spinulae. Hindleg (Fig. 3) uniform; metatrochanter with long spine-like tooth, in some specimens with one additional minute tooth; femora moderately thickened (in holotype 4.5 times as long as wide), longest spine near midlength; basal row consisting of 8-10 short teeth, distally increasing in length; distal row consisting of 
8-11 teeth distally decreasing in length; anterodistal row absent (a single minute tooth can be present). Metatibia stout, straight, with strong dentition at flexor side.

Laterotergites moderately sloping to almost horizontal. Tergite 5 about 2.2 times as broad as long. Tergite 7 about 1.6 times as long as tergite 6, and 1.2 times as long as broad. Abdominal sternites unmodified. Proctiger (Fig. 4) slender, lateral wings hardly developed, base with paired fields of short, fine setae. Paramere (Fig. 5) elongated, slender, especially the entire distal part; apex downcurved and narrowly rounded; basal part dorsally with 3 short setae; distal part ventrally with two rows of setae, setae of lateral row very long the distalmost one reaching apex.

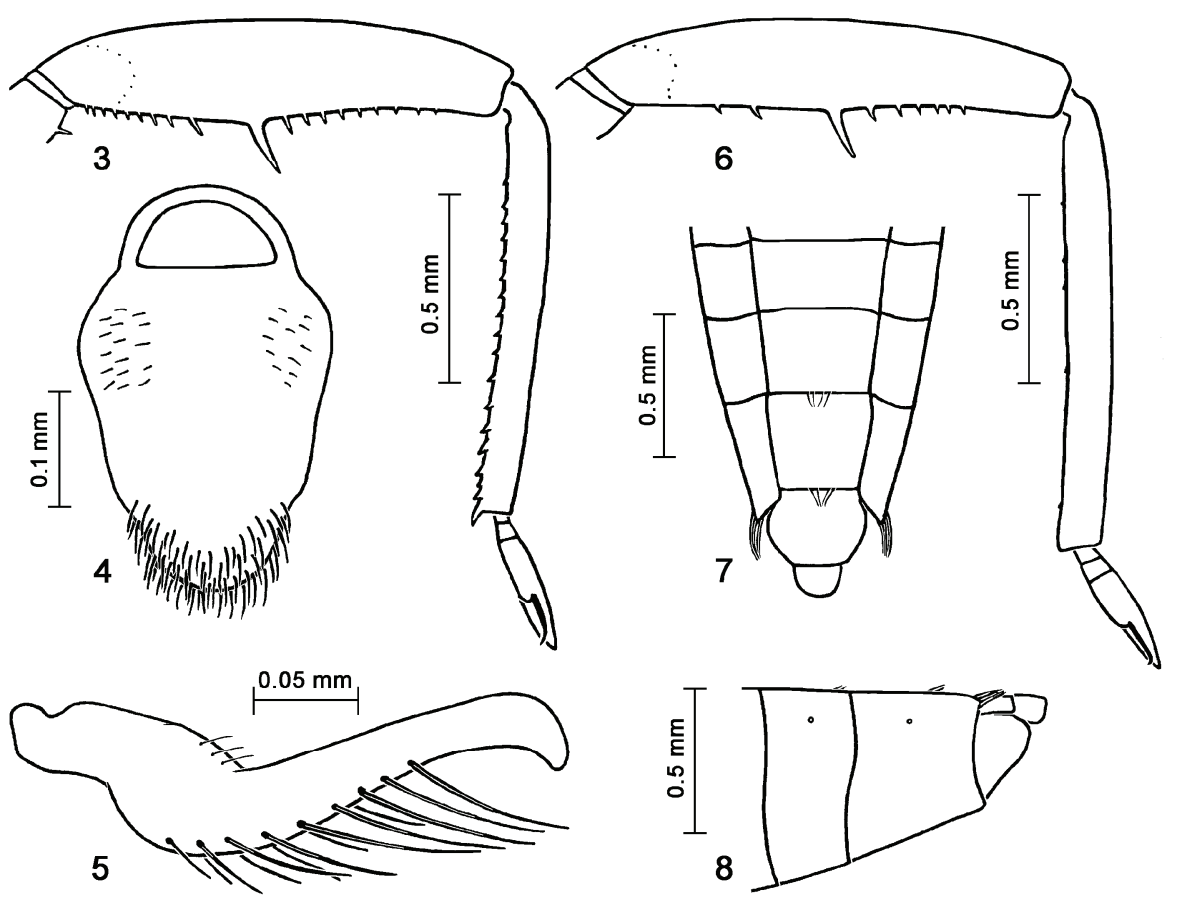

Figs 3-8. Rhagovelia freitagi sp. n. 3 - hindleg of male; 4 - proctiger of male; 5 paramere; 6 - hindleg of female; 7, - posterior part of abdomen of female, dorsal view; 8 the same, lateral view. (Pilosity omitted in Figs 3 and 6, partly omitted in Figs 7 and 8).

APTEROUS FEMALE. Measurements of paratypes $(n=6)$ : Body length 2.78 3.06; maximum body width (at metapleura) 1.00-1.09. Head width $0.72-0.73$. Pronotum length 0.19-0.22, width 0.81-0.89. Mesonotum length 0.56-0.66. Metafemur width $0.22-0.23$

Colour (Fig. 2). As in male.

Pilosity. Not much different from male. Connexival corner with small tuft of black setae. Tergites 6 and 7 (sometimes also 5) with a small group of medium-long setae at middle of hind margins. 
Structures. Body slender, abdomen slightly broader than in male. Head broader than anterior margin of pronotum. Proportions of head length, pronotum length, and mesonotum length similar as in male; mesonotum along midline 2.6-3.2 times as long as pronotum.

Mesofemur without modifications. Metatrochanter without teeth (or rarely with 1 minute tooth). Metafemur (Fig. 6) more slender than in male, with similar armature, but basal row with only 2-5 shorter teeth, distal row with 7-9 teeth. Metatibia with few minute denticles surpassing pilosity, straight.

In dorsal aspect (Fig. 7) abdomen moderately slender; lateral margins of connexiva slightly convex. Laterotergites moderately sloping; connexival margins 2-4 slightly thicker than 5-7. Tergites 1-7 slightly, transversely convex. Tergite 8 and proctiger pointing straight posteriad. Tergite 5 about 2.1 times as wide as long; tergite 7 about 1.1 times as long as tergite 6 and about 1.2 times as wide as long; tergite 8 slightly shorter than tergite 7 . Connexival corner in lateral view weakly acute, almost rectangular. Gonocoxa plate-like. Proctiger small, knob-like.

MACROPTEROUS MORPHS unknown.

COMPARATIVE NOTES. Colour and metafemoral armature of $R$. freitagi $\mathrm{sp} . \mathrm{n}$. resemble those of two species from Borneo, $R$. tebakang and $R$. samarinda Polhemus et Polhemus, 1988, although the latter species has fewer teeth and its metatrochanter lacks a spiny tooth. However, these two species possess broad, flattened juga (plates on each side of rostrum base), whereas the jugum of $R$. freitagi sp. n. is narrower and sloping towards antennal tubercles. Further differences between $R$. freitagi $\mathrm{sp}$. $\mathrm{n}$. and $R$. tebakang are: procoxa without black spinulae in both sexes in $R$. freitagi sp. n. (versus black spinulae present in $R$. tebakang); paramere of $R$. freitagi $\mathrm{sp}$. $\mathrm{n}$. with very slender distal part, moderately curved apex, and very long setae (versus distal part with broad base, strongly curved, pointed apex and rather short setae in R. tebakang; compare Polhemus \& Polhemus, 1988: fig. 123); metatibia of female of $R$. freitagi sp. n. with fine, sparse dentition (versus strong, dense dentition in $R$. tebakang); in connexival corner of (apterous) female of $R$. freitagi sp. n. slightly acute, almost rectangular (versus terminating in a short acute angle in $R$. tebakang). The more or less developed groups of setae at the hind margin of the female's tergites 6 and 7 are not mentioned in the description of $R$. tebakang by Polhemus \& Polhemus (1988).

ETYMOLOGY. This species is dedicated to Prof. Hendrik Freitag, limnologist at Ateneo de Manila University, the Philippines.

NOTES. The type locality (Saen Monourom City, Dak Dam Village, Dak Dam Waterfalls, $12^{\circ} 24.646^{\prime} \mathrm{N}, 107^{\circ} 18.604^{\prime} \mathrm{E}, \mathrm{h}=811 \mathrm{~m}$ ) is a recreational area frequently visited by tourist for its waterfalls. It has patches of secondary growth forest and is surrounded by agricultural area (Figs. 9, 10). The river is very muddy as a result of soil erosion from surrounding agricultural farming.

At present there are only three species of Rhagovelia recorded from Cambodia. Rhagovelia inexpectata Zettel, 2000 (according to Zettel et al., 2017) and R. sumatrensis Lundblad, 1933 (unpublished data) differ strongly from the new species by a comparatively long pronotum of the apterous morphs (mesonotum length at most 2.5 
times pronotum length), strongly infuscated mesocoxae, and - most of all - by some thick short setae at the mesofemoral base in males (Zettel, 2000). Four species of Rhagovelia are known from Laos and Vietnam. A key to the species of the $R$. sarawakensis group from these three countries is presented below.

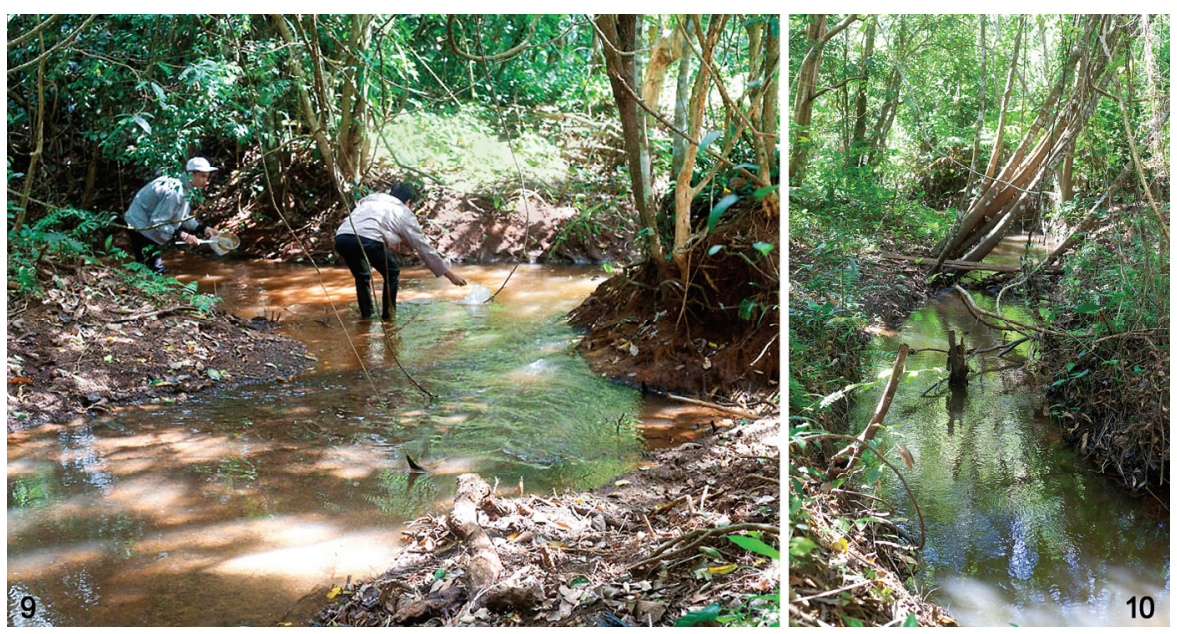

Figs 9-10. Habitats of Rhagovelia freitagi sp. n. at the type locality (C) C.V. Pangantihon).

\section{Key to the species of the Rhagovelia sarawakensis group recorded from Cambodia, Laos and Vietnam}

Many characters apply only to the common apterous morphs (characters marked with "apt"); therefore not all macropterous specimens can be identified with this simplified key. Users should bear in mind that several more undescribed species occur in Indochina (A.D. Tran, personal communication), which will be described in forthcoming publications.

1 Pronotum long, covering mesonotum (apt) as in macropterous morph. Metafemur of males strongly enlarged. Two species from Vietnam (Zettel \& Tran, 2004)

\section{Rhagovelia papuensis group}

- Pronotum short; mesonotum fully exposed (apt). Metafemur of males weakly to moderately enlarged (Rhagovelia sarawakensis group) 2

2 Yellow colour of metafemur at flexor side expanding to distal half, reaching or surpassing longest tooth. Small, stout species. - Male: metafemur more thickened than in other species of the region; mesofemur at base of flexor side with relatively stout, but rather long setae. Female: connexivum slightly sinuate, but otherwise simple (apt). Vietnam, Thailand R. caudata Nguyen et Tran, 2016

- Yellow colour of metafemur restricted to its base ... 3

3 Males

- Females 
4 Mesofemur with some short stout setae on flexor side near base. Basal row of metafemur consisting of ca. 14-21 teeth

- Mesofemur on flexor side with row of slender setae of subequal length. Basal row of metafemur consisting of ca. 8-14 teeth .....

5 Paramere with very slender, ventrally curved apex. Widespread species

R. sumatrensis Lundblad, 1933

- Paramere with broad, almost straight apex. Thailand, Laos, Vietnam, Cambodia

R. inexpectata Zettel, 2000

6 Paramere with straight apex. Tergites with rather long, dense, oblique pilosity (apt) Vietnam, Thailand ............................................. R. bisinuata Nguyen et Tran, 2016

- Paramere with curved apex (Fig. 5). Tergites with short, appressed pilosity and rows of oblique setae (apt). Cambodia R. freitagi sp. $\mathrm{n}$.

7 Abdomen strongly modified: laterotergite 3 with a smooth, shiny swelling (apt); laterotergites 6-7 with dense brush of brown setae (apt); tergite 8 laterally with long posterolaterally directed hairs. Vietnam, Thailand R. bisinuata Nguyen et Tran, 2016

- None of these characters present

8 Mesocoxa yellow. Pronotum shorter than head at midline (apt). Mesonotum 2.6-3 times as long as pronotum (apt). Tuft of hairs at connexival corner more prominent than in the following species. Cambodia

R. freitagi sp. $\mathrm{n}$.

- Mesocoxa strongly infuscated, brownish. Pronotum longer than head at midline (apt). Mesonotum not more than 2.5 times as long as pronotum (apt)

9 Tergite 8 matt (apt); mesonotum usually 2.2-2.5 times as long as pronotum (apt). Widespread species R. sumatrensis Lundblad, 1933

- Tergite 8 posteriorly shiny (apt); mesonotum usually $2.0-2.1$ times as long as pronotum (apt). Thailand, Laos, Vietnam, Cambodia R. inexpectata Zettel, 2000

\section{ACKNOWLEDGEMENTS}

The authors thank Harald Bruckner (Natural History Museum Vienna) for masking the stacking images (Figs 1, 2). The third author thanks Sophany Phauk, Chhorn Soksan, Doeurk Bros and Sin Sopha of the Department of Biology, Faculty of Science, Royal University of Phnom Penh, for the possibility to participate in an excursion to the type locality.

\section{REFERENCES}

Nguyen, X.Q. \& Tran, A.D. 2016. Descriptions of two new species of Rhagovelia (Heteroptera: Gerromorpha: Veliidae) from Vietnam. Raffles Bulletin of Zoology, 64: 389-396.

Polhemus, D.A. 2017. An initial survey of aquatic and semi-aquatic Heteroptera (Insecta) from the Cardamom Mountains and adjacent uplands of southwestern Cambodia, with descriptions of four new species. Tijdschrift voor Entomologie, 160: 89-138.

Polhemus, J.T. 1990. Miscellaneous studies on the genus Rhagovelia Mayr (Heteroptera: Veliidae) in Southeast Asia and the Seychelles Islands, with keys and descriptions of new species. Raffles Bulletin of Zoology, 38(1): 65-75.

Polhemus, J.T. \& Polhemus, D.A. 1988. Zoogeography, ecology, and systematics of the genus Rhagovelia Mayr (Heteroptera: Veliidae) in Borneo, Celebes, and the Moluccas. Insecta Mundi, 2 (3-4): 161-230. 
Zettel, H. 2000. Rhagovelia inexpectata sp. nov., a sibling species of $R$. sumatrensis from Southeast Asia (Heteroptera: Veliidae). Entomological Problems, 31(2): 175-178.

Zettel, H., Phauk, S., Kheam, S. \& Freitag, H. 2017. Checklist of the aquatic Hemiptera (Heteroptera: Gerromorpha and Nepomorpha) of Cambodia, with descriptions of new species of Microvelia Westwood, 1834 and Ranatra Fabricius, 1790. Aquatic Insects, 38(1-2): 21-48. DOI: https://doi.org/10.1080/01650424.2017.1332372

Zettel, H. \& Tran, A.D. 2004. Two new species of Rhagovelia (Heteroptera: Veliidae) from Viet Nam: first records of the R. papuensis group from south-eastern Asia. Tijdschrift voor Entomologie, 147: 229-235. 